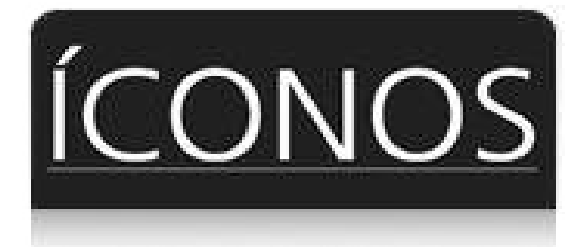

Iconos. Revista de Ciencias Sociales

ISSN: 1390-1249

revistaiconos@flacso.edu.ec

Facultad Latinoamericana de Ciencias

Sociales

Ecuador

Sugerencias Bibliográficas

Iconos. Revista de Ciencias Sociales, núm. 9, abril, 2000, pp. 128-130

Facultad Latinoamericana de Ciencias Sociales

Quito, Ecuador

Disponible en: http://www.redalyc.org/articulo.oa?id=50900912

- Cómo citar el artículo

- Número completo

- Más información del artículo

- Página de la revista en redalyc.org

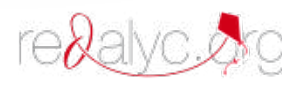

Sistema de Información Científica

Red de Revistas Científicas de América Latina, el Caribe, España y Portugal Proyecto académico sin fines de lucro, desarrollado bajo la iniciativa de acceso abierto 


\section{Sugerencias bibliográficas}

\section{La Descentralización}

AA.VV., La descentralización. Diálogo para el desarrollo, PNUD, BM, BID, Nueva Sociedad, Caracas, 1999 , pp. 219

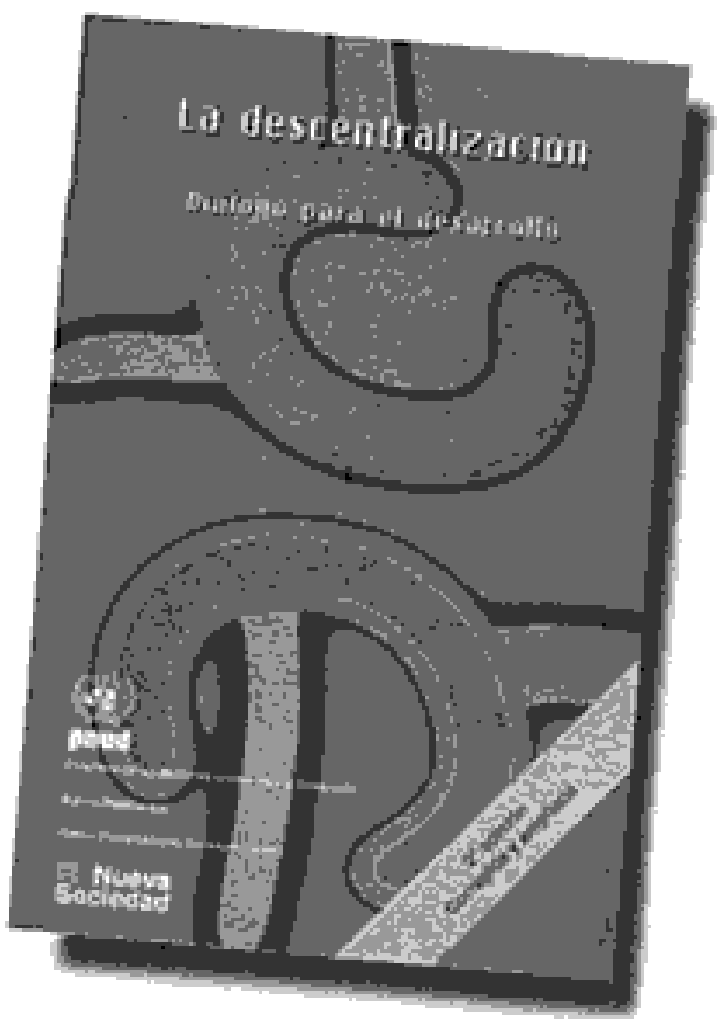

Desde perspectivas y puntos de vista variados, este libro recoge varias propuestas que pretenden identificar las bases para una agenda acerca de la descentralización, la cual permita a los distintos actores (gobierno central, local, organismos internacionales, etc.) ir adaptando sus políticas generales y sus planes de desarrollo a los procesos de descentralización al interior de cada país.

Las propuestas y conceptos recogidos en este libro se enmarcan dentro de la discusión y el debate que procura el avance y el perfeccionamiento de la descentralización como estrate- gia fundamental de la reforma del Estado en América Latina. Entre otros temas, se hace un breve recuento de la evolución político-administrativa del Estado (tomando como ejemplo el caso venezolano), se describe las transferencias de competencias y servicios a los gobiernos estadales y la devolución de funciones a los municipios.

Los temas y capítulos presentados a lo largo del libro contribuyen a la discusión y profundización de la problemática de la descentralización, como un tema crucial dentro de la agenda de los paises de América Latina.

\section{Cruzar las fronteras}

Leiser, Eckart, Cruzar las fronteras. En búsqueda de una antropología post-hegemónica, MomoSapiens, Rosario (Argen.), 1998, pp. 248

Este libro parte de las más rutinarias concepciones académicas de la subujetividad para llegar al psicoanálisis y, desde allí, reflexionar sobre la noción de frontera como muro que pretende imponer y frenar el desarrollo del pensamiento. Este libro también va más allá de la psicología y enfoca el proyecto más general de lo que suele llamarse "antropología" y en la que conceptos como dispositivos de poder de Foucault y hegemonía tienen importancia. El autor destaca la existencia de espacios ambiguos, reñidos y hasta exterritoriales fuera de los sistemas hegemónicos tradicionales de poder, $y$ busca en el cruce de fronteras la respuesta de una antropología post-hegemónica.

Las preocupaciones que guian a Leiser son más que nada prácticas, conciernen a diversos modos y a diversos impasses para disciplinar (en el sentido de Foulcault) las subjetividades en ésta época de la cultura occidental. Lo que está en juego cuando se refiere a "postestructuralismo" no es tanto lo referente a una nueva moda o corriente intelectual, sino a si la historia va a inclinarse por la diferencia o por lo que Leiser nombra como hegemonía. El autor encuentra esta problemática en el corazón mismo del psicoanálisis.

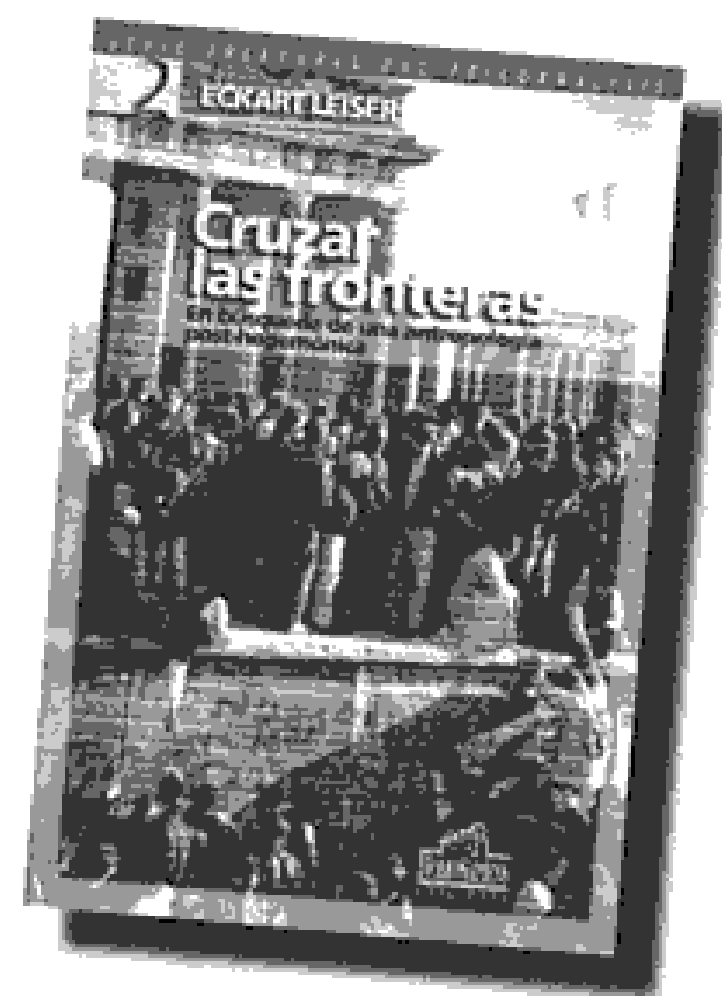




\section{El fin de los tiempos}

Carrière, J.C., Delumeau J., Eco H., y Jay Gould, El fin de los tiempos, ANAGRAMA, Barcelona, 1998, pp. 283

El fin de los tiempos es el resultado de cuatro apasionantes e interesantes entrevistas hechas al paleontólogo americano Stephen Jay Gould; al historiador de los miedos en Occidente, Jean Delumeau; al hombre de teatro y de cine Jean-Claude Carriere; y al semiólogo italiano Umberto Eco.

Lo recogido en este trabajo son cuatro grandes testimonios de nuestros tormentos contemporáneos, que examinan los diferentes significados, religiosos y profanos, de la idea del fin de los tiempos. De esta manera, Gould, Delumeau, Carriere y Eco reflexionan $\mathrm{y}$ presentan, con ciencia, humor $\mathrm{y}$ lucidez, los desafios que nos trae el presente milenio.

La idea del fin de los tiempos, como explica Delumeau, procede directamente de la Biblia que, en oposición a las sabidurías griegas y orientales, inventó el concepto

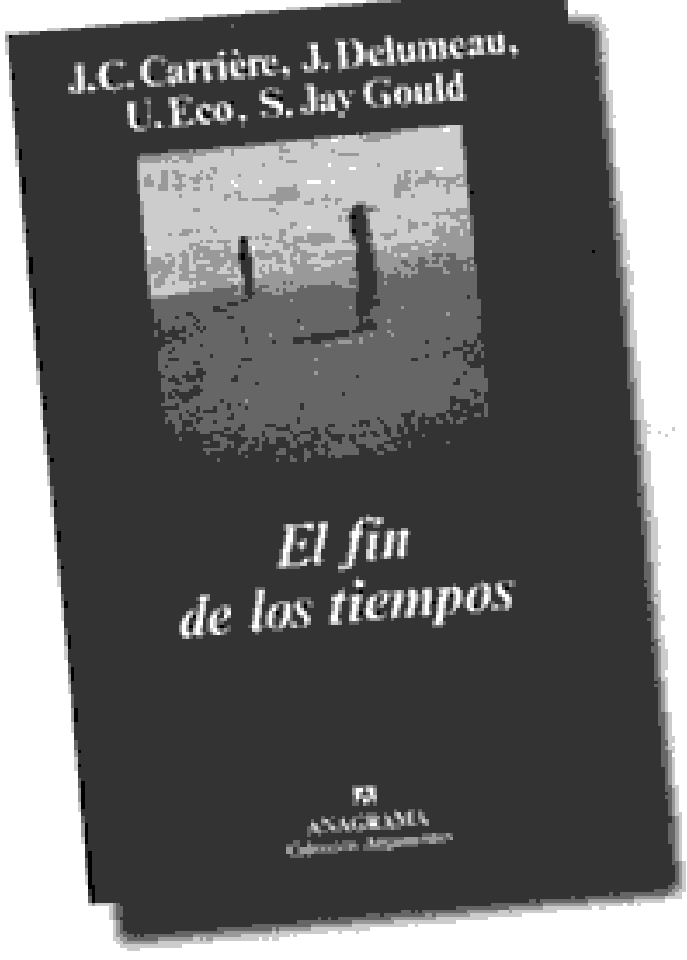

del tiempo lineal, dotado de un principio y de un fin. Lo que se aprecia en este libro es cómo esta concepción del tiempo ha influido en todo el desarrollo del pensamiento occidental, hasta el más profano. Delumeau y Gould destacan, entre otros aspectos, cómo ciertas profecías han causado tanto impacto e impresión durante los dos mil años transcurridos: expectativas "milenaristas" han suscitado muchos más trastornos y pasiones que el final del primer milenio, que dejó, contrariamente

\section{El animal público}

DELGADO, Manuel, El animal público, 3ra. ed., ANAGRAMA, Barcelona, 1999 pp. 218

Este libro de Manuel Delgado, laureado con el premio Anagrama al mejor ensayo, nos lleva directamente a reflexionar y repensar sobre lo urbano; o, en otras palabras, busca dar cuenta de la vida urbana desde una perspectiva interdisciplinaria y decididamente antropológica, destacando su importancia como objeto de in-

a los tópicos, indiferente a la mayor parte de los cristianos.

El declive del mundo cristiano y la secularización de la sociedad han ahuyentado del imaginario occidental estas creencias y miedos típicamente religiosos. Sin embargo, como señala Umberto Eco, el pensamiento del fin de los tiempos es hoy más característico del mundo laico que del mundo cristiano. Este último lo convierte en objeto de meditación y el mundo laico finge ignorarlo, pero este pensamiento lo obsesiona. Dicho de otra manera, ya nadie interpreta los signos de los tiempos como signos del fin de los tiempos descrito en el Apocalipsis.

Cada uno de estos cuatro grandes testigos recuerda a su manera que cualquier época agitada genera sus propios fantasmas de aniquilación. Seguimos estando marcados ineluctablemente por el sello de la concepción judeo-cristiana de la flecha del tiempo, en el sentido de la historia y el fin de los tiempos.

vestigación científica y desde una óptica alejada y fuera de cualquier dogmatismo.

Esta obra abre el camino hacia unas ciencias sociales que se ocupen de lo incierto, incalculable y oscilante que hay en la vida cotidiana, lo inconsistente y lo humano que emerge incansable e inesperadamente aquí y allá, en la calle, en aquel lugar donde se puede experimentar la desolación y el desamparo más absolutos, pero también donde es posible esca- par, desobedecer, desviarse, desertar individualmente o en masa. Es el espacio

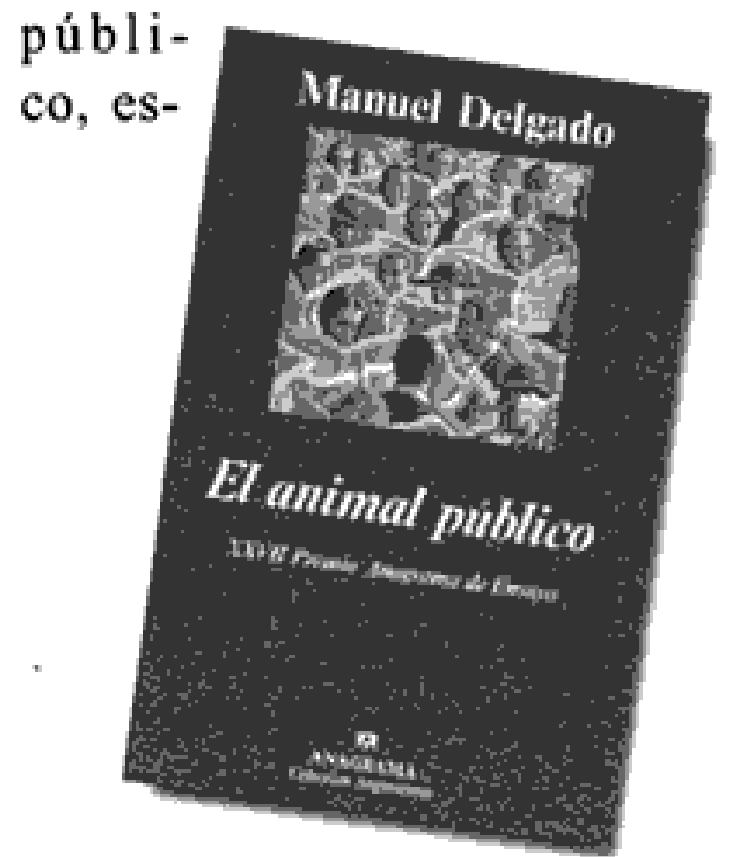


pacio rigurosamente vigilado por todos los poderes, por ser el más predilecto de las emancipaciones y las estampidas.

Delgado, en esta interesante y decidora obra, plantea la urgencia de una antropología que atienda a todo lo que en la ciudad puede ser visto flotando en su superfi- cie: estructuras, ejes que organizan la vida social en torno suyo, pero que raras veces son instituciones estables, sino una pauta de fluctuaciones. Se sugiere una antropología distinta, una disciplina que estudia los espacios públicos, esas extensiones en las que se dan todo tipo de bifurcaciones, esce- nificaciones que no se debería dudar en calificar de coreográficas, donde el animal público, ese personaje de múltiples rostros, pasa su tiempo desplegando ardides, confundiéndose con el terreno, aprovechando los accidentes de los paisajes por los que transita.

\section{Diccionario de los sentimientos}

Marina, José Antonio, y Marisa López P., Diccionario de los sentimientos, Edit. ANAGRAMA, Barcelona, pp. 468

¿Qué siente un humano cuando dice que siente envidia? ¿Qué experimenta un humano cuando dice que experimenta amor? Cuando dice que experimenta naklik (amor en lengua esquimal), ¿está sintiendo lo mismo? Aunque este libro habla de palabras y no es exactamente de linguística, aunque habla de sentimientos y no es de psicologia, aunque habla de culturas y no es tampoco de antropologia, es, como dicen sus autores, leído del principio al final como una narración y del final al principio como un diccionario.

Este diccionario de los sentidos destaca la importancia del lenguaje sentimental, el cual guarda una enorme cantidad de información sobre el ser humano, recopilada, organizada, tramada por muchas generaciones. Para sus autores, José Antonio Marina y Marisa López, cada idioma guarda en sus ocultas bodegas un longevo archivo de la experiencia de cada sociedad.

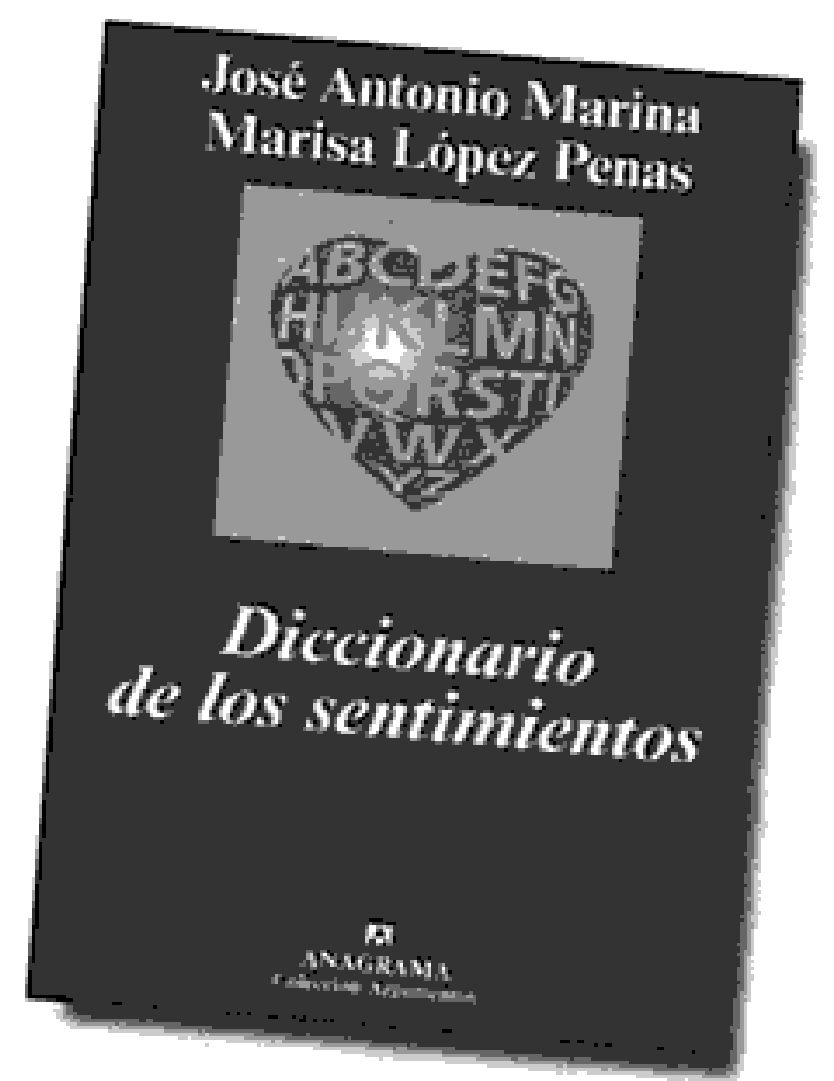

El léxico contiene una teoría completa del ser humano, de su comportamiento, sus motivos, sus esperanzas, incluso de su propia estructura mental. Hay una profunda psicologia popular inmersa en los intersticios del lenguaje, desde donde se encamina parte de nuestra vida afectiva.

Antes que un diccionario, antes que un texto sobre los sentimientos, como dicen sus autores, este libro es un homenaje a la lengua, a todas, festivo y solemne a la vez. Es un diccionario cognitivo que busca mostrar las relaciones del léxico con el conocimiento. Es la cartografia de un viaje de ida y vuelta. Es un léxico castellano que busca correspondencias o contradicciones en otras lenguas. Es un estudio de palabras que quiere ser una investigación sobre la realidad. 